\title{
La difusión de memes de contenido político durante la tercera ola de la COVID-19
}

Memes distribution during COVID-19 third wave

JOSÉ RÚAS ARAÚJO

UNIVERSIDADE DE VIGO

HTTPS://ORCID.ORG/0000-0002-1922-9644

TALÍA RODRÍGUEZ-MARTELO

UNIVERSIDADE DE VIGO

HTTPS://ORCID.ORG/0000-0002-7633-0394

JULIA FONTENLA-PEDREIRA

UNIVERSIDADE DE VIGO

HTTPS://ORCID.ORG/0000-0001-8770-4761

RESUMEN: En el año 2020 se inició la crisis sanitaria de la COVID-19 en todo el mundo acompañada de una amplia difusión de noticias, fake news y contenidos humorísticos que tratan diferentes aspectos del suceso. Esta investigación analiza la proliferación de los memes y publicaciones cómicas de contenido político durante la tercera ola de la pandemia con la hipótesis de que este tipo de contenidos son un reflejo de la actualidad y materializan la crítica social. A partir de un análisis cuantitativo y de contenido de las cuentas principales, se han seleccionado memes y publicaciones de perfiles destacables de usuarios de Twitter e Instagram. Esta información se ha codificado en función de su diseño, discurso y distribución, con la intención de identificar las publicaciones de mayor alcance sobre sobre la pandemia y con mayor índice de engagement. En conclusión, se puede afirmar que los contenidos meme y humorísticos constituyen una válvula de escape de la ciudadanía ante las crisis mediatizadas y catalizan las emociones, aportando un sentimiento de comunidad expresado a través de un lenguaje común y universal. Los discursos representados en los memes responden a los temas de mayor preocupación de la sociedad siendo, en este caso, las medidas gubernamentales restrictivas. 
Palabras clave: COVID-19, Coronavirus, memes, fake news, dircurso político, desinformación, redes sociales.

ABSTRACT: In 2020, the COVID-19 worldwide health crisis began accompanied by a wide dissemination of news, fake news and comedy content related with different aspects of the event. This research analyzes the proliferation of memes and funny publications with political content during the third wave of the pandemic. Starting hypothesis is that this type of content is a reflection of current events and materializes social criticism. Th Throught a quantitative and content analysis of the main accounts, it have been selected memes and publications of remarkable profiles of Twitter and Instagram users. This information has been coded according to their design, discourse and distribution, with the intention of identifying the publications about pandemic of this type with the greatest reach and with the highest engagement rate. In conclusion, it can be affirmed that memes and humorous contents constitute an release valve for citizens in the face of mediatized crises and catalyze emotions, providing a sense of community, expressed through a common and universal language.

Key words: COVID-19, meme, fake news, political speech, disinformation, social networks.

\section{INTRODUCCIÓN}

El presente trabajo es fruto de un estudio que analiza el contenido de los memes relacionados con la COVID-19 durante la tercera ola que coincide en fechas con la campaña de vacunación. El interés suscitado por las diferentes informaciones acerca de la pandemia vertidas en redes sociales ha tomado múltiples formatos de expresión. En este sentido, la circulación de memes para informar, desinformar y como crítica ante gobiernos y autoridades, sirve de termómetro social para identificar las opiniones y preocupaciones más extendidas por la población.

\subsection{FAKE NEWS Y CORONAVIRUS}

La crisis derivada de la pandemia del coronavirus COVID-19 ha avivado, tanto en España como a nivel mundial, el debate sobre la necesidad pública de protegerse contra la difusión de bulos y noticias falsas.

Internet es la segunda vía de acceso a informaciones de contenido pseudocientífico, inexacto o engañoso y, en España, 2/3 de los ciudadanos buscan información sobre salud a través de la red, lo cual ha llevado a hablar de la fake-science, ante la necesidad de curación de contenidos científicos (López-Borrull y Ollé, 2019; Molina-Cañabete y Magallón-Rosa, 2020), observada ya antes del estallido del Coronavirus.

Los bulos sobre salud se han incrementado desde 2019, según afirman los profesionales de la sanidad en el II Estudio sobre Bulos en Salud en España. Estos contenidos falsos sobre salud no son una novedad (Dharshanram, Kumar y Iyapparaj, 2018), como tampoco lo es la búsqueda de información sobre salud en Internet (Dai, Sun 
y Wang, 2020), ya que constituye una práctica habitual -lo que se conoce como el fenómeno Dr. Google.

Pero el inédito impacto sanitario, social, económico y político de esta pandemia ha multiplicado la desinformación (Salaverría, Buslón, López-Pan et al., 2020).

En febrero de 2020, la Organización Mundial de la Salud (OMS) anunciaba la propagación de dos tipos de epidemia: una provocada por el brote del coronavirus y otra por la proliferación y el alcance de las informaciones sobre esta infección. Para esta última, la OMS utilizó el término infodemia, acuñado previamente por Rothkopf (2003), que hace referencia a la sobreabundancia de una información, cierta, precisa y otra no, que dificulta que las personas encuentren fuentes y orientación confiables cuando las necesiten (World Health Organization, 2020).

Los bulos generados en Europa sobre la COVID-19 en marzo y abril del 2020 (los dos meses más críticos para la mayoría de los países europeos) se estima que representan ya 1 de cada 5 del total de casos de fake news detectadas desde 2015 (Abellán, 2020).

Pero los números en España tampoco dejan lugar a dudas. El Gobierno del Estado cifraba en más de 200 los «eventos de desinformación grave» sobre el Coronavirus registrados durante el primer mes de la declaración del Estado de Alarma (concretamente entre el 15 de marzo y el 15 de abril de 2020), por la Oficina de Coordinación Cibernética (Reche, 2020), computando sólo los de contenido puramente sanitario. Porque si de lo que se habla es de bulos relacionados, en general, con la crisis derivada de la pandemia, entonces la cifra se eleva a más de 1.000 durante el mismo período (Abellán, 2020).

Sin embargo, los bulos no son un hecho novedoso, sino que responden, en su mayoría, a reglas y técnicas ya descritas en la propaganda clásica, como son la exageración, simplificación y ridiculización del adversario a través de la utilización del humor como arma (Domenach, 1950) y también como desahogo, válvula de escape y expresión de rebeldía frente a la imposición de distintos regímenes (Arias, 2017 y Escobar, 2015).

De hecho, en la distancia que separa la falsedad de la mentira-dependiendo de la intencionalidad- hay distintos matices que pueden medirse empleando la «cinta métrica de la mentira» de Higgins y Wardle (citado por Redondo, 2018) que va desde el ejercicio de un periodismo deficiente hasta la propaganda, pasando por el rumor, las noticias basura o pseudociencia, las noticias falsas, la provocación, el humor, la parodia y la sátira, elementos que integran buena parte de los memes que circulan en la actualidad por la red y que el propio Barthles (1977) considera como una práctica lúdica.

La competencia por las audiencias ha llevado a considerar el entretenimiento como parte de las rutinas periodísticas y oferta de la programación audiovisual (Brants, 1998), consolidando el infoentretenimiento, como género híbrido entre la información y el entretenimiento, hasta la existencia de programas dedicados íntegramente, a parodiar la política, marcados por el humor y la espectacularización (Pelliser y Pineda, 2014).

Asimismo, la denominada era de la posverdad ha alterado el actual ecosistema mediático y supone nuevos retos y amenazas para el periodismo (Rúas, Curiel y López, 2020), en la disputa por imponer un relato dominante de la crisis. Un relato y marcos alternativos, que cuestionan la verificación de hechos (fact-checking) y el combate de las noticias falsas (fake news) como práctica democrática.

El contexto político y mediático actual explica, al menos en parte, la búsqueda de alternativas y nuevas retóricas, modos, herramientas y estilos de comunicación, adaptados a internet y los medios digitales, entre los cuales se encuentran los memes.

De hecho, el componente lúdico se ha utilizado para combatir la desinformación, a través del diseño de newsgames (García-Ortega, García-Avilés 2021), definidos como 
videojuegos en los que la simulación se mezcla con frecuencia con la sátira política (Galloway, 2004).

Videojuegos algunos de ellos basados en la teoría de la inoculación (McGuire, 1964), que enseñan a fabricar bulos como antídoto para identificarlos, similares al elaborado por Roozenbeek y Van der Linder (2018), con la intención de conocer el proceso de elaboración de noticias falsas, para prevenirse contra ellas y evitar ese contagio y la transmisión, señalado por Richard Dawkins (2000), en su obra El Gen Egoísta, para referirse a los memes y las ideas que circulan por la sociedad.

\subsection{MEMES, CULTURA, LENGUAJE Y POLÍTICA}

Richard Dawkins (citado por Rúas y García, 2018) acuñó en 1976 la palabra meme para indicar que, si los genes son las unidades mínimas de transmisión de la herencia biológica, los memes constituyen unidades mínimas de transmisión de la herencia cultural y el conocimiento colectivo.

Hoy en día, los memes hacen referencia a las ideas o conceptos expresados habitualmente de forma gráfica, audiovisual o textual, que se difunden y reproducen a sí mismos con la ayuda de internet las redes sociales, logrando captar la atención de los usuarios, gracias a su componente netamente humorístico y en tono de broma (Davison, 2012), que acaban convirtiéndose en virales.

Las redes sociales han favorecido este nuevo tipo de comunicación más sincrética y visual conocida como Imemes (Vélez, 2007), término utilizado para describir los memes que circulan por internet (Shifman, 2014; Wiggins, 2019) y que, en sentido político, han derivado hacia una práctica social y cultural, hasta conformar lo que algunos autores ya denominan memecracia (Rodríguez, 2014).

De hecho, es el medio digital el que llevó a Kozinets (2010) a referirse a la netnografía de los memes, para señalar el estudio de la etnografía en los espacios digitales que requiere que la selección de materiales sea relevante, activa, interactiva, heterogénea y rica en datos.

Entre los usuarios de internet, meme es «un término popular para describir el rápido consumo y propagación de una idea particular presentada como un texto escrito, imagen, lenguaje 'movimiento' o alguna otra unidad de 'cosa' cultural» (Knobel y Lankshear, 2007: 202). También como fragmentos de la cultura popular, en palabras de Stryker (2011), quien asegura que los memes conforman un nuevo lenguaje, complejo, a través del cual la gente comunica de forma visual, breve y concisa, opiniones y emociones.

Los memes son considerados como un género discursivo según el concepto de Bakhtin (2008), forman parte del orden de discurso y, a su vez, el lenguaje -tanto visual como textual- forma parte de las imágenes marco (García-Huerta, 2014) propias de los memes en Internet, donde el componente iconográfico resulta fundamental. De ahí que algunas de las tipologías básicas para su clasificación (Pérez Salazar, 2017), propongan diferenciarlos entre imágenes con texto incrustado e imágenes secuenciales $\mathrm{o}$ microhistorietas.

Aun así, esta combinación dificulta el establecimiento de un marco teórico adecuado para los memes ante la falta de un vocabulario ortodoxo y rigurosamente descriptivo, de ahí la propuesta de estudiarlos a través de un método integrador que permita analizar, representar y comparar los diversos fenómenos etiquetados.

En ese sentido, Davison (2012) propone separarlos en tres componentes: manifestación (cómo se manifiesta, en cuanto a signos observables externamente), comportamiento (la acción realizada por el individuo que lo recibe y, si lo considera, 
transmite y/o manipula) e ideal (el concepto o la idea transmitida). La distinción entre cuál de estos tres aspectos está siendo replicado y cuál adaptado es lo que permite distinguir sus características, que son, básicamente: su influencia y sus diferencias de comportamiento y replicación, que según este autor implican otras dos categorías, uso y vista. A su vez, esta clasificación nos permitirá comprobar qué memes son falsos y verdaderos y a qué tipo de manifestación responden, como arte, entretenimiento o producto con una clara intencionalidad política.

En este sentido, Pérez Salazar et al. (2014, p. 80) definen los memes como un «recurso empleado por grupos específicos, a partir de procesos de apropiación y reinterpretación de un conjunto de signos en circulación en diversos entornos del ciberespacio».

Otros autores, como Shifman y Thelwall (2009), proponen el análisis de los memes a través del seguimiento del rastro que dejan en Internet en el tiempo y el espacio, combinando análisis cualitativos y cuantitativos para identificar y evaluar las diferentes versiones de un meme y su presencia, evolución y propagación a través de la red e, incluso, su traducción a distintos idiomas, con la intención de analizar su potencial.

En cualquier caso, más allá de su poder como vehículos de transmisión, GarcíaHuerta (2014) señala la necesidad de considerarlos teniendo en cuenta los procesos culturales, comunicativos y de apropiación, a través de los cuales los usuarios de Internet añaden un propósito e intencionalidad en su consumo y difusión, siguiendo la teoría de la influencia de los medios sobre la sociedad y la cultura (Hjarvard, 2008). De ahí la propuesta de analizar el metadiscurso -el discurso sobre el discurso- y el poder poder simbólico (Craig, 1999) generado por los memes, a través de la interacción de los usuarios, incluyendo no solamente los aspectos retóricos y semióticos, sino también los relacionados con la cibernética y la teoría crítica de la comunicación.

\subsection{LOS MEMES EN TIEMPOS DE PANDEMIA}

A partir de la consideración de un marco teórico interdisciplinario, el análisis de los memes producidos durante la pandemia del Coronavirus ha mostrado cómo estos discursos digitales refuerzan la discriminación y la exclusión, propagan ideologías globales. Los memes también son vehículo para la expresión colectiva de emociones y han sido un recurso semiótico para reforzar procesos súbitos y masivos de coerción semiótica (como la sana distancia o el confinamiento), o para contribuir a la reconversión semiótica que ha implicado la nueva normalidad (Salgado Andrade, 2021).

Durante la primera y segunda ola de la COVID-19, así como en las diferentes fases del confinamiento, los hábitos de consumo audiovisuales se vieron modificados, identificándose un aumento de la audiencia de la televisión (Montaña, Ollé y Lavilla, 2020). Los nuevos hábitos de consumo televisivo en general, y de las noticias en particular, han cambiado la forma en que los ciudadanos otorgan relevancia a la información. De hecho, las redes sociales como principal vía de acceso a la información y el infoentretenimiento conforman este paradigma mediático en el que tiene lugar la difusión de memes (Casero-Ripollés, 2020).

La interacción en redes sociales ha fomentado la difusión de desinformación a cerca del Coronavirus y en plataformas como Tik Tok han proliferado contenidos, sátiras y memes sobre las vacunas (Basch et al., 2021), tema que ha tenido un amplio recorrido durante la tercera ola, entre otros.

Los memes no constituyen simplemente un producto humorístico y trivial y pueden tener una intencionalidad política, gracias al gran potencial de que disponen como modalidad de participación ciudadana en la discusión pública (Gutiérrez, 2020), dada la 
característica esencial de los mismos, que permiten condensar un hecho político en un contenido breve, poderoso y efectivo (Re, 2014), o como artefactos discursivos y formas de persuasión, tal y como señala Hugntington (2016).

De hecho, Shifman (2014) hace una clasificación en tres categorías de los memes como forma de participación política: 1. memes como persuasión o defensa política, referidos especialmente a las campañas electorales, 2. memes como acción de base, relacionados con su papel central y su potencial vinculación personal y política y 3 . memes como modelos de expresión, como ruta accesible, barata y agradable para expresar opiniones políticas o la posición de un usuario ante cualquier acontecimiento.

Por su parte, Gutiérrez Rubí (2014) destaca las potencialidades de los memes para el activismo político, por la innovación constante de sus lenguajes y formatos, su carácter crítico y universal (lo cual facilita su viralidad) y la construcción colaborativa de los internautas, logrando de este modo el desarrollo de una nueva narrativa para el activismo político.

\subsection{REDES SOCIALES Y CONTENIDO GENERADO POR EL USUARIO (CGU).}

El paradigma comunicativo generado por el entorno digital ha propiciado que la interacción entre usuarios, así como la interacción entre audiencias y medios de comunicación, sea una realidad que tiene lugar de forma principal en las redes sociales. Estas plataformas ofrecen múltiples vías de acceso según la tipología de sus contenidos.

De esta forma, encontramos redes originariamente basadas en la imagen como Instagram, o en texto como Twitter. Sin embargo, en la actualidad, la mayoría de las redes son plataformas integrales que en los últimos años han ido priorizando los espacios destinados al vídeo, prueba de ello es el caso de Tik Tok que está en pleno auge marcando tendencias y aumentando seguidores.

En este espacio, los memes y contenidos similares encuentran una vía de distribución y consumo. Debido a sus características intrínsecas, los memes están dotados de una maleabilidad que hace posible que su replicación se adapte al discurso del usuarioemisor y este es perfectamente decodificado por el usuario-receptor, tanto por la información referencial que contiene como en el nuevo uso que le aplica el nuevo emisor. En otra de las múltiples fórmulas en las que un meme logra su difusión y viralidad, simplemente se propaga el mismo mensaje y cada usuario da conformidad a la idea expresada con este gesto (Fontenla-Pedreira, Rúas-Araújo y Conde-Vázquez, 2020).

Ambas fórmulas suponen un nivel de compromiso con el acto comunicativo y enlazan con los principios de contenido generado por el usuario (CGU) en el que los consumidores se convierten en prosumidores. Este nuevo prosumer se define por su capacidad y filiación en la producción de contenido de diversa índole que será distribuido a través de las redes sociales (López-Galán, Rodríguez-Castro y Campos Freire, 2019).

El CGU es una demanda de los nuevos públicos que ante un entorno mediático convergente quieren participar en la conversación y ser creadores de contenido (Maroto y Rodríguez-Martelo, 2018). Por una parte, precisan de espacios o plataformas en las que los contenidos sean fácilmente difundidos y que ofrezcan herramientas para la participación de los usuarios (Fernández Castrillo, 2014). Esta participación se materializa mediante la creación de contenido. La capacidad de expansión que Jenkins, Ford y Green (2015) conceptualizan al hilo de la narrativa transmedia ilustra cómo la comunicación actual precisa de estos elementos, en tanto que los usuarios asimilan y replican contenido que difunden, expresando de este modo su propio discurso.

Esta capacidad de mutación y adaptación a un discurso nuevo, que mantiene su comprensión a pesar de las variaciones, actúa de forma similar a la idea de 
intercreatividad de la web expresada por Berners Lee (1999, citado por Fernández Castrillo, 2014). En consecuencia, el hecho de que son publicaciones generadas y replicadas por usuarios no profesionales es una característica esencial que los memes comparten con el CGU.

\section{HIPÓTESIS, OBJETIVOS Y METODOLOGÍA}

La presente propuesta de investigación parte de la hipótesis de que la difusión de memes y contenidos humorísticos de contenido político en las redes sociales se articula como una respuesta de los agentes sociales ante los momentos de crisis o estrés de la ciudadanía. Además, se plantea cómo en el caso de la COVID-19 existe una relación directa entre los contenidos humorísticos y las noticias difundidas en los medios de comunicación, así como de informaciones falsas sobre la pandemia. En este punto han servido de apoyo trabajos similares como el de Norstrom y Sarna (2021).

Para comprobar la hipótesis de partida se han establecido los siguientes objetivos de investigación:

OG1: Identificar contenidos humorísticos y memes sobre la pandemia, distinguiendo los basados en informaciones o hechos verdaderos de los falsos (fakes), y estableciendo una relación con las informaciones a las que hacen alusión.

OG2: Investigar los memes de mayor alcance durante la tercera ola de la pandemia y campaña de vacunación estableciendo una línea temporal y analizando cuando se presenta mayor incidencia.

OG3: Analizar los memes con mayor índice de engagement dentro de la muestra resultante.

Como objetivos específicos complementarios al análisis expuesto se ha determinado identificar la naturaleza de las publicaciones estudiadas, su diseño, producción y difusión.

Para esta aproximación a los memes como objeto de estudio, hemos combinado un análisis cuantitativo, de cálculo de las publicaciones de contenido político con más engagement en Twitter e Instagram, con un enfoque de los memes bajo la perspectiva del análisis de discurso, con referencias en trabajos anteriores (Mancera y Pano, 2013, Martínez y Piñeiro, 2016; Wiggins, 2019), teniendo en cuenta su difusión a través de diferentes modos semióticos (textual, verbal gestual, pictórico), propios del denominado análisis de discurso multimodal (Dynel, 2021), que amplía el estudio del lenguaje en combinación con otros recursos ( $\mathrm{O}^{\prime}$ Halloran, 2012).

Además de la categorización antes referida de Shifman (2014), de los memes en función de su grado de participación política y su potencialidad (Gutiérrez Rubí, 2014), para su clasificación y análisis hemos considerado los cuatro dominios en los que los memes adquieren sentido según Kress y Van Leeuwen (2001): discurso (quién está involucrado, qué es lo que sucede, dónde y cuándo) diseño (cómo se muestra y qué elementos añade), producción (cómo se organiza y articula, los recursos que utiliza para materializar el diseño) y distribución, en cuanto a su potencial de recodificación.

Igualmente, siguiendo a Rolán y Martínez (2017), se realizó una categorización de los memes según el emisor (perfil y tipo de usuario), tipo de mensaje textual (respuesta, menciones y hashtags empleados), visual (contenido y fuente de referencia de la imagen) o audiovisual, además de las interacciones generadas.

El corpus de análisis propuesto se compone de los memes y contenidos de índole crítica, en tono humorístico o satírico sobre el Coronavirus, difundidos a través de las redes sociales, principalmente a través de Twitter e Instagram, entre el 26 de diciembre 
de 2020 y el 15 de marzo de 2021. Esta secuencia temporal coincide con la denominada tercera ola de la pandemia y con la campaña de vacunación.

Para la selección de memes se han analizado un total de veinte cuentas de usuarios en español e inglés, agregadores de contenido y medios de comunicación (@obichero, @cabronazi,@proscojoncio, @ceciarmy, @diostuitero, @norcoreano, @mulacam, @gerardotc, @xuxipc, @senoritapuri, @yisuscrist, @ralphianismo, @fuckjerry, @cabronazi,@vidamoderna,@vistoenlasredes,@coronaVid19,@postureoespañol, @ralphianismo,@epicfunnypage, @sainthoax) en las que se han localizado cincuenta publicaciones con un rendimiento o alcance superior a los 5000 likes o shares.

Para definir el corpus de análisis se realizó una primera aproximación intuitiva (Arbeláez y Onrubia, 2014) mediante un barrido de los perfiles en redes sociales más habituales en la difusión de este tipo de contenidos y en función del criterio numérico.

Una vez seleccionados los perfiles que contienen las publicaciones objeto de estudio, se han integrado aquellas que se sitúan por encima de las 5.000 interacciones y en la franja temporal propuesta en la ficha de codificación para proceder a su clasificación e identificar en qué área temática están encuadradas.

La ficha diseñada muestra en el parámetro de la producción la fecha de publicación y el emisor para el que se han determinado tres categorías posibles usuario, agregador de contenido o medio de comunicación. En cuanto al diseño, se ha determinado examinar si los contenidos analizados son texto, imagen o vídeo. En función del discurso se ha establecido una trazabilidad entre el contenido y la información de referencia que ha dado lugar al meme o contenido humorístico satírico y determinar si la alusión responde a una información real o falsa.

De esta forma, se ha establecido que los contenidos relacionados con la COVID19 se pueden dividir en 4 subcategorías: datos sobre la emergencia sanitaria, normativas e infracciones, vacunas y campaña de vacunación y datos económicos y laborales.

Por último, consideramos de especial interés analizar el alcance de las publicaciones y su efectividad, medida a través de la variable engagement $\mathrm{o}$ interactividad. El engagement ha sido considerado inicialmente como la atención hacia un objeto y representación simbólica de estados mentales subjetivos (Dahlgren, 2006), a través de figuras en las redes sociales (principalmente Me gusta, Compartir y Comentar) que pueden ser registradas y clasificadas para su medición.

Aunque resulta complicado conceptualizar el engagement, ya que se basa en lo emocional, se puede definir como el resultado de un proceso perceptivo y, por ello, cada individuo elabora su significado de forma personal.

Cuando los usuarios aprecian un contenido, bien porque nace un vínculo afectivo positivo o negativo entre ellos, la posibilidad de que este contenido sea comentado y compartido con otros seguidores aumenta, y con ello, el crecimiento de la búsqueda de información sobre el tema en cuestión en la web, frecuentando otras redes sociales o espacios de la misma temática. Este hecho desencadena una relación emocional con el contenido y por lo tanto, el engagement se puede entender como «un comportamiento ante los medios caracterizado por un número alto de exposiciones al contenido y por el aumento de la frecuencia de acceso al mismo, acompañados por la búsqueda y exploración de contenidos en la red relacionados con el mismo» (Tur-Viñes, 2015:48).

En la presente comunicación se han considerado los memes con mayor engagement de las cuentas analizadas para realizar su posterior análisis de contenido. Para calcular esta variable, se ha tenido en cuenta la siguiente fórmula tomada de Ballesteros (2019), de acuerdo con las tres dimensiones establecidas por Mollen y Wilson (2009): el engagement cognitivo (estado mental caracterizado por un procesamiento cognitivo activo), el engagement personal (la satisfacción derivada de su uso y relevancia) y el 
engagement emocional (la experiencia senso-emocional presente en las interacciones): $\mathrm{E}=\mathrm{ni}(\mathrm{nr}+\mathrm{nc}+\mathrm{nco}) / \mathrm{np}$, donde $\mathrm{E}=$ Engagement $; \mathrm{ni}=$ Número de interacciones; $\mathrm{nr}=$ Número de reacciones. $\mathrm{nc}=$ Número de comentarios; $\mathrm{nco}=$ Número de compartidos; $\mathrm{np}=$ Número de publicaciones.

Existe un elevado número de memes que tratan de forma explícita o tangencial el tema del Coronavirus. A partir de la técnica de muestreo anteriormente detallada se ha seleccionado un corpus ajustado al marco temporal comprendido entre el 26 de diciembre de 2020 y el 15 de marzo de 2021. Una vez recogida de información según la ficha diseñada, se han procesado y seleccionado los memes con mayor índice de likes, comentarios y más veces compartidos, para exponerlos al análisis de tipo cualitativo, que ha permitido calcular el engagement y el rendimiento de estas publicaciones.

De estos perfiles se han extraído 50 ejemplos de contenidos que hacen referencia a informaciones o sucesos relacionados con la COVID-19 y se han procesado de la siguiente forma:

Tabla 2. Ejemplo de tratamiento de los contenidos analizados. Elaboración propia.

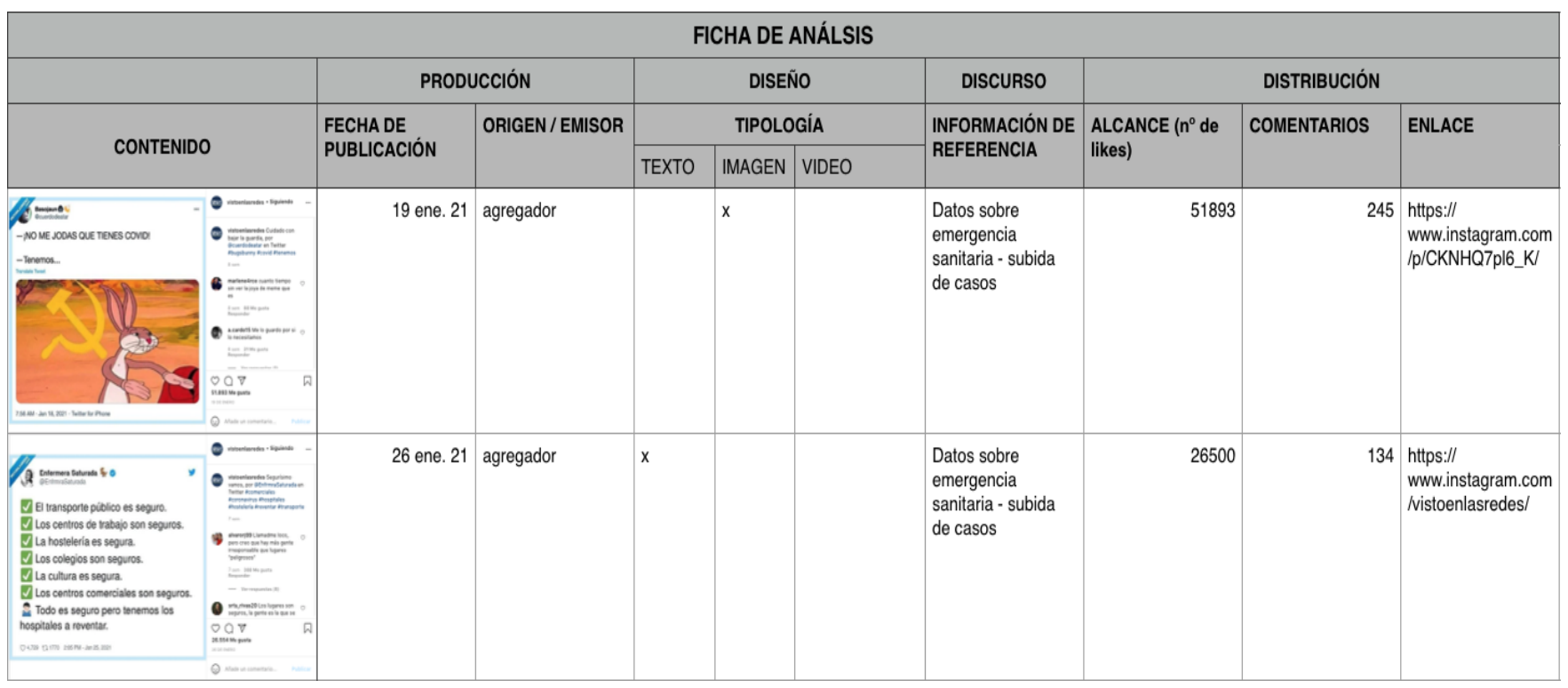

\section{RESULTADOS}

La exploración inicial de los resultados se ajusta a la adecuación de la clasificación a las cuatro áreas temáticas preconcebidas y la pertinencia de los ejemplos, acorde con la definición de meme expuesta en el marco teórico. En este sentido, ante un contenido humorístico o satírico, el concepto de meme se hace patente en tanto que estos contenidos son moldeables y replicables. La circulación masiva acaba garantizando la mutación contextual, ya que las ideas expresadas en los memes tienden a ser de fácil transmisión y adaptación para nuevos discursos.

El hecho de adaptar y replicar un contenido está sujeto a la vinculación que surge entre el usuario y la capacidad de expresar una nueva información, utilizando el meme como vía de expresión (Bakthin, 2008, Salgado Andrade, 2021) o entre el usuario y su conformidad con la idea que expresa mediante la replicación del contenido (FontenlaPedreira, Rúas-Araújo y Conde-Vázquez, 2020). En ambos casos asistimos a un fenómeno que pone de manifiesto el compromiso de los usuarios con este tipo de contenidos. 
En el caso de los memes y piezas humorísticas relacionadas con el COVID-19, la universalidad y magnitud del acontecimiento facilita la difusión, asimilación y comprensión de las ideas expresadas. Además, la sucesión de acontecimientos permite comprobar, tal y como señalan Shifman (2014) y Gutiérrez Rubí (2014), quienes exponen que los memes sirven como vías de expresión política y activismo.

Los post se han procesado en función de su diseño ya sean texto, imagen o video. La distribución de esta categoría es muy semejante (el $36 \%$ se corresponde con publicaciones tipo texto, el $34 \%$ con imagen y el $30 \%$ con vídeo), pero cabe señalar que los contenidos en vídeo tienen un rendimiento mayor, ya que las redes sociales, además de contabilizar los likes, shares y comentarios, también contabilizan el número de reproducciones.

Un $42 \%$ de los memes analizados se corresponden con el área temática relativa a las medidas adoptadas por los diferentes gobiernos, restricciones e infracciones. El 36\% se corresponde con contenidos que hacen referencia a los datos y actualidad sobre la emergencia sanitaria. Un $14 \%$ a las noticias relacionadas con las vacunas y la campaña de vacunación; y en menor medida, apenas un $8 \%$ versa sobre datos económicos y laborales y la crisis derivada de la COVID-19.

Los memes analizados responden a informaciones difundidas a través de los medios de comunicación. Al realizar la trazabilidad de las noticias y comprobar el origen connotativo de los memes, se ha detectado que no existe una correlación directa entre estos contenidos y la proliferación de fake news en los ejemplos analizados. De hecho, la correspondencia entre los memes y la actualidad informativa es paralela de forma que, a través de los mismos, se critica y se da seguimiento a las noticias, en ocasiones con datos exagerados y como licencia humorística más que como intencionalidad discursiva.

En relación al alcance de las publicaciones se puede destacar que, tal y como se aprecia en la gráfica que sigue, se presenta un mayor índice de interacción en las fechas cercanas a efemérides como el día de fin de año, el 14 de febrero debido al día de San Valentín y las elecciones catalanas, momentos destacados de la actualidad como la dimisión del Ministro de Sanidad, Salvador Illa (26 de enero de 2021), o los disturbios en las ciudades de Barcelona y Madrid (finales de febrero de 2021).

Se ha puesto el foco de atención en el contexto español, pero es preciso matizar que los perfiles estudiados son de ámbito nacional e internacional, en español e inglés, que son los idiomas que más difusión tienen en la red. Esta cuestión adquiere gran relevancia ya que aporta una variable a considerar en el terreno de la globalización de los mensajes publicados. 


\section{Ilustración 1. March again meme. ${ }^{1}$}

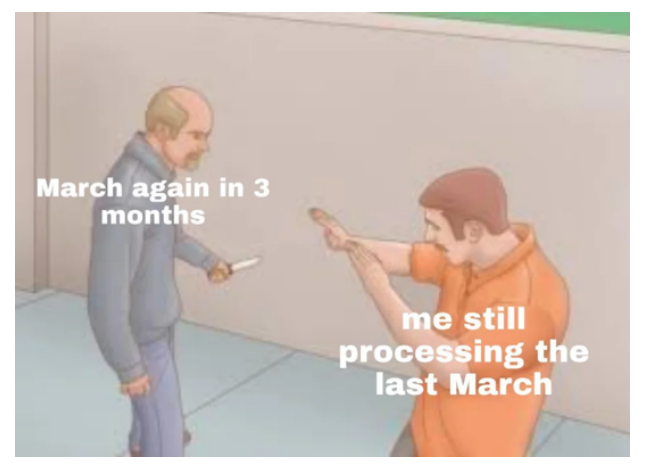

En el ejemplo correspondiente a la ilustración 1, observamos uno de los memes más utilizados en diversas páginas de Internet y lo encontramos adaptado a múltiples situaciones de la actualidad y en muchos idiomas.

Durante la crisis sanitaria se ha utilizado en diferentes lenguas para ilustrar la incapacidad de procesar el paso del tiempo en los diferentes confinamientos. Este es un ejemplo muy representativo del concepto de la plasticidad de los memes -similar a la plasticidad del cerebro, por continuar con la asociación realizada por Dawkins en su descripción de los memes como ideas que circulan por la sociedad- como facilitadores expresivos de ideas, ya que aporta un significado dual tanto por la información adaptada como por el subtexto o connotaciones que encierra el uso de la imagen concreta. De esta forma, el público que lo recibe y decodifica entiende la idea central representada y realiza una nueva lectura a partir del texto incrustado cambiante.

En el caso de España, la réplica de contenidos relacionados con Fernando Simón, Director del Centro de Coordinación de Alertas y Emergencias Sanitarias y responsable de las ruedas de prensa relativas a la pandemia, ha tenido una elevada repercusión y su imagen ha suscitado multiplicidad de memes relacionados con la pandemia o con una traslación de significados en la que se utiliza su imagen para hacer memes sobre momentos diferentes a la crisis sanitaria.

Un ejemplo ilustrativo de ello es el Trendic Topic (TT) que circuló por la red social Twitter durante los meses de enero y febrero de 2021, «Vamos a morir todos», cuya utilización hacía referencia a las declaraciones de Fernando Simón. También se han difundido contenidos similares que expresan la disociación entre los datos de la pandemia y sus predicciones.

\footnotetext{
${ }^{1}$ Fuente: https://www.reddit.com/r/meme/comments/k3p2ho/march_in_3_months/
} 


\section{Ilustración 2. Meme de Fernando Simón tras su comparecencia el 11 de enero que generó el Trendic topic de Twitter VAMOS A MORIR TODOS y Meme sobre las declaraciones de Fernando Simón en enero 2021.}
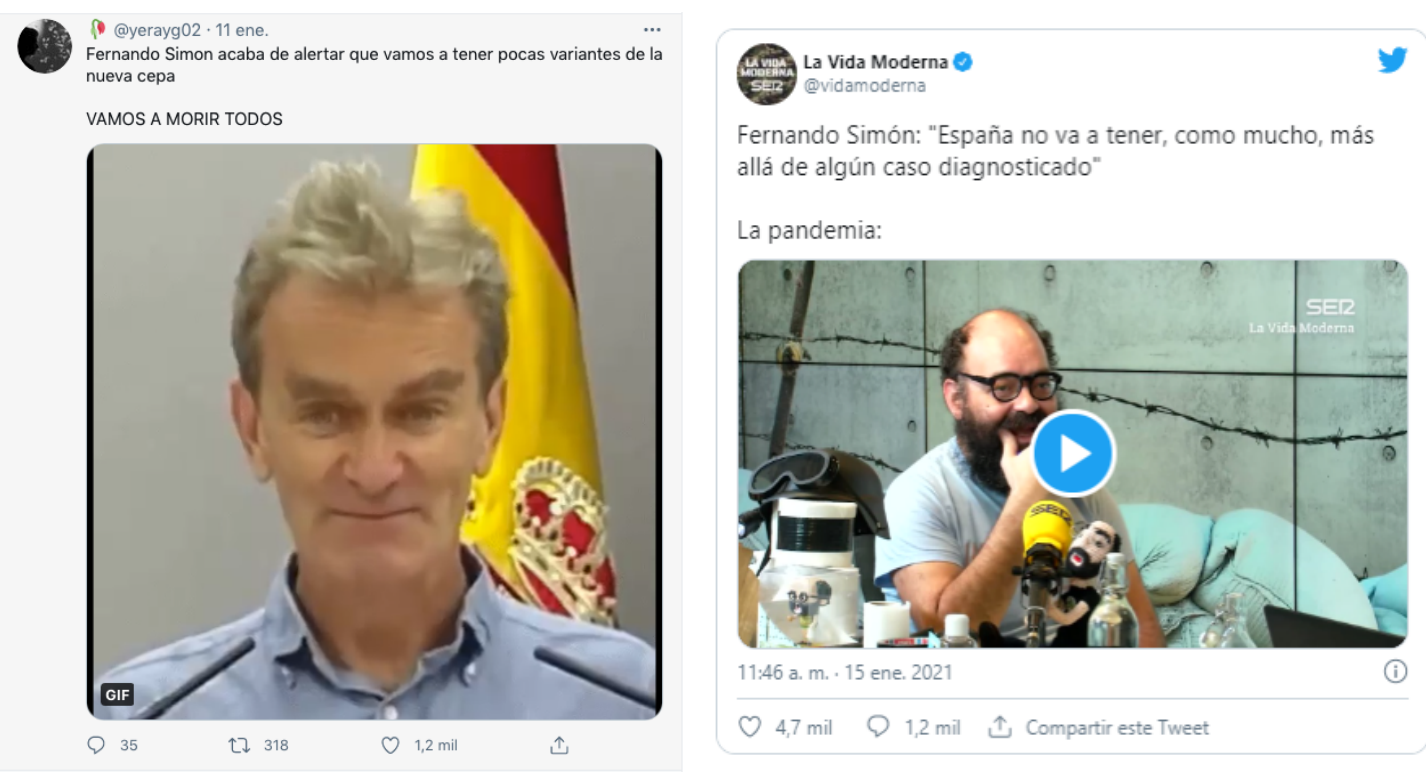

Fuente: https://twitter.com/search?q=Vamos\%20a\%20morir\%20todos\%20TT\&src=typed_query

En lo referido al engagement, aplicando la fórmula de Ballesteros (2019) diferenciaremos las cifras en función de la red social de la que procede el meme. Así, los memes con mayor difusión en el período analizado para la red social Instagram alcanzan cifras entre el 2,3\% y 4,2\% para los post con imágenes, y entre el 2,32\% de compromiso y el $1,21 \%$ para los post con vídeo (un porcentaje alto teniendo en cuenta que los índices de un buen ratio de engagement en Instagram se sitúa según el último estudio de Hootsuite (2020) entre el 1\% y el 5\% -siempre teniendo en cuenta que puede influir el perfil del que estemos hablando, el tamaño de su audiencia o el tipo de contenidos que publique-.

Para la red social Twitter, la herramienta de marketing digital Rival IQ, establece un porcentaje menor de compromiso para las publicaciones en esta red social, situando la cifra de referencia en torno a un $0,45 \%$, encontrándose las publicaciones relativas a la COVID-19 analizadas en un $0,51 \%$, lo que significa que los memes también tienen una buena acogida entre la audiencia.

Ambas redes sociales coinciden en el hecho de que todas las publicaciones con mayor difusión y comentarios pertenecen a las mismas fechas y temática y, también, en un aspecto muy interesante: los usuarios establecen conversación con otros usuarios, ya sea perteneciente a su círculo de amigos o desconocidos, otorgándoles voz sin ningún tipo de silenciamiento de comentarios. Además, encontramos que todos estos memes se publican en horas estratégicas para sus audiencias, con el objetivo de obtener un mayor alcance y ratio de engagement y maximizando sus probabilidades de redifusión. Además aparecen duplicados en las diferentes redes y son reenviados a través de la mensajería privada de WhatsApp.

En cuanto a los contenidos, los memes con mayor engagement giran en torno a información relativa a rebrotes en las diferentes comunidades autónomas, el toque de queda («Los bares servirán Cruzcampo para evitar aglomeraciones», «He cerrado más bares que el Gobierno de Sanidad»), las medidas adoptadas durante la tercera ola y las diferentes vacunas de las distintas farmacéuticas. Por otro lado, los memes con mayor engagement relativos a la vacunación en España se acompañan del uso de hashtags, 
\#Pfizer \#BionTech \#Moderna \#AstraZeneca y coinciden con el trendic topic del 27 de diciembre, \#VacunaCovid, momento en el que se inicia la vacunación en la Unión Europa y en el que tampoco faltan los memes relativos a la primera mujer vacunada en el mundo, Margaret Keenan, de Inglaterra, o de Araceli, la primera vacunada en España.

Por otro lado, adquieren un alto grado de compromiso los memes de contenido negacionista de diferentes personajes públicos, a modo burla: «Nos están utilizando como a cobayas, metiéndonos en el cuerpo una cosa que no sabemos ni lo que es».

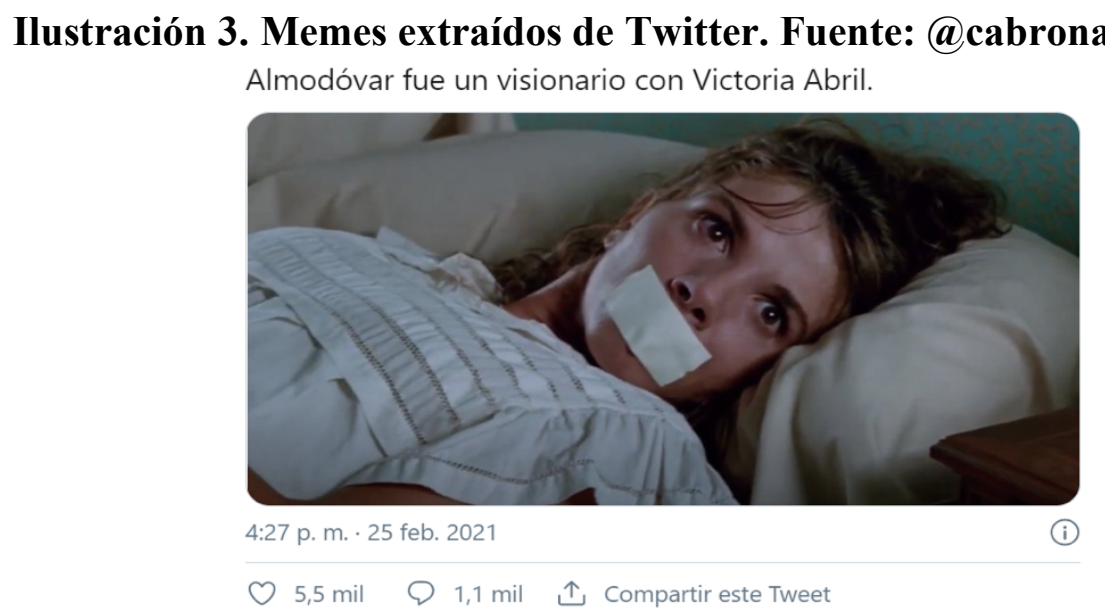

https://cadenaser.com/ser/2021/01/15/sociedad/1610711515_665912.html

Asimismo, no faltan los comentarios de los usuarios reaccionando a ellos en los que de nuevo se agudiza el ingenio «pa anticuerpo el que se me está quedando», «vamos a morir todos», «si pillo el coronavirus es por ir descalzo», o «al día siguiente que abran las discotecas las resacas conseguirán el verdadero confinamiento general».

\section{Ilustración 4. Memes extraídos de Twitter}

No habrá ningún contagio este domingo entre las 2 y las 3 de la mañana

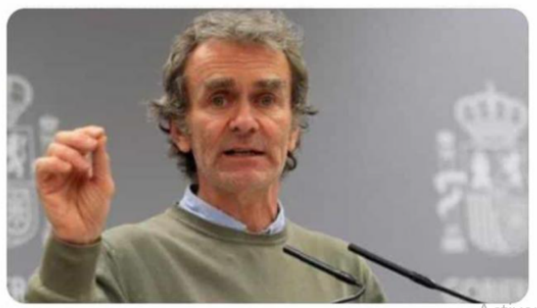

España saca su propia vacuna.

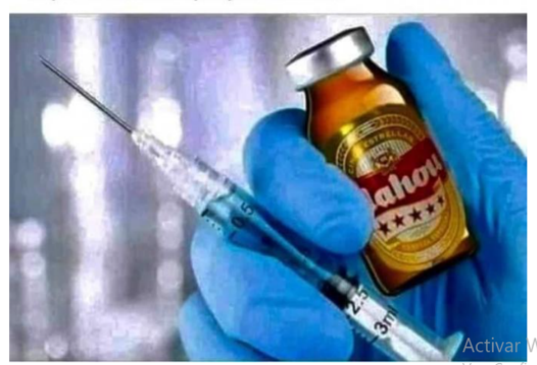

SE FILTRAN LAS PRIMERAS IMÁGENES DEL PACIENTE VOLUNTARIO QUE PROBÓ LA VACUNA DE ASTRA ZENECA

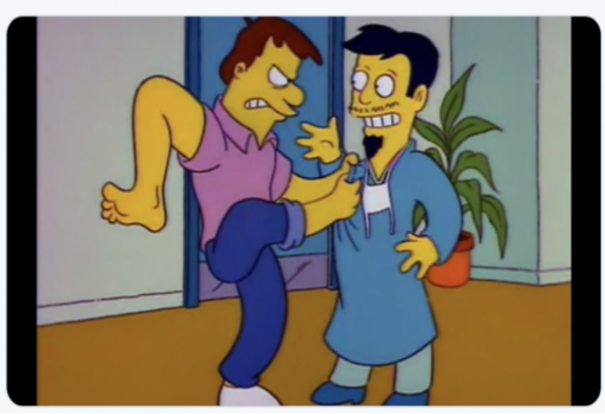

Moe de Triana $\$$ @moedetriana

Me he hecho un test del coronavirus de los que ha comprado el Gobierno y me ha salido niña. 


\section{CONCLUSIONES Y DISCUSIÓN}

La difusión de memes a través de redes sociales constituye una práctica habitual que encontramos a diario en este tipo de plataformas. Los memes que consumimos y replicamos sirven para expresar nuestra conformidad o disconformidad con determinadas ideas.

Esta investigación sostenía la hipótesis de que la difusión de memes de contenido político se corresponde con la respuesta de la sociedad a determinados momentos de estrés y su proliferación está relacionada con la actualidad de la información de la crisis concreta. Al mismo tiempo, entre los objetivos de este trabajo se planteaba la identificación de los memes y contenidos humorísticos (OG1), investigar los de mayor alcance y su nivel de engagement (OG2), así como explorar las informaciones a las que hacen alusión (OG3).

Al respecto, señalamos que el cumplimiento de los objetivos planteados permite establecer que los memes y contenidos de humor versan sobre los temas de actualidad de la pandemia de forma relacional, directa y simultánea. La plasticidad semántica de los múltiples significados y el subtexto adquirido con cada mutación permite ampliar rangos de información y vislumbrar cómo existe una mayor incidencia en los temas relevantes que tienen connotaciones emocionales, como por ejemplo las consecuencias de la pandemia y las medidas restrictivas.

Una vez expuestos los resultados se comprueba la hipótesis de partida. Efectivamente, los memes son un contenido que difundido y/o retrabajado articulan una respuesta compartida ante la realidad del momento. En mayor medida, cuando esta realidad afecta negativamente a la población utiliza esta vía de comunicación como expresión de ideas y sentimientos compartidos. En este sentido, los memes actúan como catalizador de emociones relacionadas con la actualidad informativa y como crítica. La difusión supone un compromiso con las ideas expresadas y con la comunidad que las replica. Cuando además de consumir, el usuario asimila, modifica y replica un meme concreto, se está sirviendo del subtexto para agregar nuevo significado a una idea ya expresada.

Tal y como hemos observado, estas mutaciones, que trascienden fronteras y superan barreras idiomáticas, otorgan a los memes una plasticidad semántica que los convierte en vehículos de expresión capaces de elaborar una conexión entre emisor y receptor en diferentes niveles explorando la crítica, la referencia a información real y la vinculación emocional a partir de la identificación del contenido concreto.

En cuanto a los niveles de compromiso encontrados, los memes han conseguido que mucha de la información transmitida a través de los medios se hiciese viral, gracias a un mensaje claro y muy fácil de entender. Al igual que durante toda la pandemia, los memes se han convertido en recurrentes durante esta tercera ola, pero esta fase ha estado caracterizada por un engagement muy alto en los contenidos relativos a la vacunación.

Además, las reacciones de los usuarios han conseguido que otra audiencia participe y que sea partícipe de esa información. Se cumplen, por tanto, las tres dimensiones de engagement de Mollen and Wilson (2009), cognitivo, personal y emocional. Las manifestaciones cognitivas se concretan en los comentarios de los usuarios sobre aspectos del contenido de los memes, y menciones a otros usuarios, convirtiéndolos en contenido interactivo a la vez que emocional, gracias al valor del entretenimiento.

En este sentido, cuando los memes son referidos a contenido político, expresan la realidad de la actualidad del momento, aportando una visión crítica de los 
acontecimientos. En el caso de la COVID-19, concluimos que la extensa circulación de memes replicados en diversas fuentes por multitud de usuarios tiene un contenido anclado a cuatro tipos de informaciones: los datos sobre la pandemia, las medidas adoptadas por el Gobierno del Estado en materia de restricciones y las infracciones que son consecuencia de las mismas, la campaña de vacunación y la realidad económica y laboral.

Asimismo, mediante este estudio se comprueba, como refieren Arias (2017) y Escobar (2015), que el humor que explora la crítica política sirve como válvula de escape para la ciudadanía expuesta a determinadas circunstancias, como son las restricciones de movilidad, por ejemplo. Los memes sobre el Coronavirus tienen una carga política evidente y su propagación sirve para aliviar la frustración y descargar la tensión provocada por un fenómeno singular.

En el caso estudiado, que se corresponde con la tercera ola y la campaña de vacunación iniciada en toda Europa el 26 de diciembre, hallamos que los contenidos replicados sirven para ilustrar la información y noticias vertidas durante este período y para reflejar el hartazgo o la incomprensión de la sociedad ante las consecuencias de las decisiones políticas, dado que la mayoría de los memes se basan en este tema. Debido a esta presencia de la crítica como ingrediente fundamental e imprescindible de los memes, son contenidos que, desde la sátira o el humor, siempre versan sobre los aspectos negativos de las noticias y vivencias de los ciudadanos.

En este sentido, los memes ayudan a configurar un lenguaje común y universal avalado por el sentimiento de comunidad que ya de por sí produce la comunicación en Internet. Este sentimiento de pertenencia se ve incentivado en la transmisión y mutación de memes y contenidos humorísticos que, en relación a la COVID-19, tratan, en su mayor parte, sobre las restricciones y sentimientos experimentados por la sociedad a raíz del confinamiento.

Finalmente, señalar que, tras el análisis realizado, observamos que la red social Tik Tok respondería también al patrón y definición de los memes, como replicadores de contenido que se difunde entre usuarios, mutando en su confección y aportando significaciones diferentes, de ahí su consideración para investigaciones futuras.

\section{BIBLIOGRAFIA}

2021, enero 13. «Vamos a morir todos»: los chistes de la nueva profecía de Simón que aterroriza a Twitter. El Español. Disponible en:

https://www.elespanol.com/social/20210113/vamos-morir-chistes-profeciasimon-aterroriza-twitter/550695941_0.html

2021, enero 15. «Twitter enfurece con Fernando Simón por acusar a la sociedad del aumento de contagios». Cadena Ser. Disponible en: https://cadenaser.com/ser/2021/01/15/sociedad/1610711515_665912.html

Abellán, Lucía. 2019, marzo 11. «El Gobierno activa una unidad contra la desinformación ante las elecciones». El País. Disponible en: https://elpais.com/politica/2019/03/10/actualidad/1552243571_703630.html

Arbeláez, Martha y Onrubia, Javier. 2014. «Análisis bibliométrico y de contenido. Dos metodologías complementarias para el análisis de la revista colombiana Educación y Cultura». Revista de Investigaciones UCM, 14 (23): 14 - 31.

Arias, E. 2017. «No existe nada más serio que el humor político». La Tercera Orilla, (5). Recuperado en:

https://revistas.unab.edu.co/index.php/laterceraorilla/article/view/3063 
Asociación de Investigadores en eSalud (AIES). 2019a. Informe EHON. ¿Cómo actuar frente al Dr. Google? Madrid: Sandoz. https://bit.ly/34dhShw

Asociación de Investigadores en eSalud (AIES). 2019b. II Estudio sobre Bulos en Salud. Encuesta a profesionales de la salud de España. Recuperado en: https://bit.ly/2Rf2v32

Bakhtin, M. 2008. Estética de la creación verbal: Actividad, discursos, pragmática, géneros, comunicación, literatura. Buenos Aires: Siglo XXI.

Ballesteros, Carlos. 2019. «La representación digital del engagement: hacia una percepción del compromiso a través de acciones simbólicas». Revista de Comunicación (18), n.1 Piura, ene/jun 2019. DOI: http://dx.doi.org/10.26441/RC18.1-2019-A11

Barthes, Roland. 1977. Image. Music. Text. New York: Hill and Wang.

Basch, C. H., Meleo-Erwin, Z., Fera, J., Jaime, C., \& Basch, C. E. 2021. «A global pandemic in the time of viral memes: COVID-19 vaccine misinformation and disinformation on TikTok». Human Vaccines \& Immunotherapeutics, 1-5.

Brants, Kess. 1998. "Who's afraid on infotaintment?». European Journal of Communication, 13(3): 315-335.

Casero-Ripollés, A. 2020. «Impact of Covid-19 on the media system. Communicative and democratic consequences of news consumption during the outbreak». El profesional de la información, 29 (2), e290223.

Costa-Sánchez, Carmen y López-García, Xosé. 2020. «Comunicación y crisis del coronavirus en España. Primeras lecciones». El Profesional de la información, 29 (3), e29034. Disponible en: https://doi.org/10.3145/epi.2020.may.04

Craig, Robert T. 1999. "Communication Theory as a Field». En: Communication Theory Vol. 9, pp.119-161. DOI:

https://doi.org/10.1111/j.1468-2885.1999.tb00355.x

Dahlgren, Peter. 2006. «Civic participation and practices: Beyond deliberative democracy». En Researching media, democracy and participation: the intellectual work of the 2006 European media and communication, Doctoral summer school, ed. Carpentier, Nico (pp. 23-34). Estonia, Tartu: University Press 2006. http://yecrea.eu/files/teaching_series_1ok.pdf

Dai, Enyan, Sun, Yiwei y Wang, Suhang. 2020. «Ginger Cannot Cure Cancer: Battling Fake Health News with a Comprehensive Data Repository»». https://bit.ly/2yyMxKs

Davison, Patrick. 2012. The language of (Internet) Memes. [En línea]. Disponible en: https://archive.org/details/TheSocialMediaReader

Dharshanram, R., Madan Kumar, P. D. y Iyapparaj, P. (2018). «Spread of health-related fake news in Tamil social media - A pilot study». Journal of Global Oral Health, 1(1): 21-24. https://doi.org/10.25259/JGOH-5-2018

Dawkins, Richard. 2000. El gen egoista. Las bases biológicas de nuestra cultura. Barcelona: Salvat Editores.

Domenach, Jean Marie. 1963. La Propaganda Política. Buenos Aires: Eudeba.

Escobar, Aliber. 2015. «Monty Python: comedia, crítica y política». Versión. Estudios de Comunicación y Política, 35: 85-99. Recuperado en: http://version.xoc.uam.mx

Dynel, M. 2021. «COVID-19 memes going viral: On the multiple multimodal voices behind face masks». Discourse \& Society, 32(2): 175-195.

Fernández Castrillo, Carolina. 2014. «Prácticas transmedia en la era del prosumidor: Hacia una definición del Contenido Generado por el Usuario (CGU)». CIC. Cuadernos De Información Y Comunicación, 19: 53-67. DOI:

https://doi.org/10.5209/rev_CIYC.2014.v19.43903 
Fontenla-Pedreira, Julia, Rúas-Araújo, José, Conde-Vázquez, Erica. 2020. «Audiencia en redes sociales de los debates televisados en las elecciones generales de abril de 2019». Revista latina de comunicación social, n. 76: 1-16. DOI:https://www.doi.org/10.4185/RLCS-2020-1434

investiga-si-existe-un-grupo-criminal-detras-de-la-campana-de-bulos-contrael-gobierno-sobre-el-coronavirus.html

Galloway,Alexander. 2004. «Social Realism in Gaming». Game Studies, 4.

García-Ortega, Alba y García-Avilés, José Alberto. 2020. «When journalism and games intersect: Examining news quality, design and mechanics of political newsgames». $\quad$ Convergence, $26 \quad$ (3): $517-536$

García Huerta, Dassaev. 2014. «Las imágenes macro y los memes de internet: posibilidades de estudio desde las teorías de la comunicación». PAAKAT: Revista de Tecnología y Sociedad, 6(4).

Gutiérrez Vidrio, Silvia y Reyna Ruiz, Margarita. 2020. «Los memes en la política: primer debate de la contienda presidencial mexicana 2018». Virtualis, 11(21): 89-108.

Hodge, Bri-Mathias. 2017. «Social semiotics for a complex world: Analysing language and social meaning». Polity Press.

Hjarvard, Stig. 2008. «The Mediatization of Society. A Theory of the Media as Agents of Social and Cultural Change». Nordicom Review, 29 (2): 105-134.

Hootsuite. 2020. Social media trends in 2020. Recuperado en: https://www.hootsuite.com/es/research/social-trends

Hungtington, Henry. 2016. «Pepper Spray Cop and the American Dream: Using Synecdoche and Metaphor to Unlock Internet Memes Visual Political Rhetoric». Communication Studies, 67(1): 77-93.

Jenkins, Henry, Ford, Sam y Green, Joshua. 2015. Cultura transmedia: la creación de contenido y valor en una cultura en red. Barcelona: Editorial Gedisa

Kozinets, Robert. V. 2010. Netnography: Doing ethnographic research online. London: Sage.

Knobel, Michele y Lankshear, Colin. 2007. «Online memes, affinities, and cultural production». En A new literacies sampler. [En línea]. New York: Peter Lang. Disponible en: http://literacyandtech.pbworks.com/f/Text. pdf\#page=11.

López-Borrull, Alexandre y Ollé, Candela. 2019. «La curación de contenidos científicos como respuesta a las noticias y a la ciencia falsas». Anuario ThinkEPI, 13.

López-Golán, Mónica, Rodríguez-Castro, Marta, y Campos Freire, Francisco. 2019. «La innovación de las radiotelevisiones públicas europeas en la comunicación digital y las comunidades de usuarios». Cuadernos.info, (45): 241-255. DOI: https://dx.doi.org/10.7764/cdi.45.1350

O’Halloran, Kay. 2012. «Análisis del discurso multimodal». ALED, 12(1): 75-97.

Mancera, Ana y Pano, Ana. 2013. El discurso político en Twitter. Análisis de mensajes que 'Trinan'. Buenos Aires: Siglo XXI.

Maroto González, Isaac y Rodriguez-Martelo, Talia. 2019. «Estrategias de desarrollo de la televisión pública española: El caso de la plataforma Playz». En La Innovación de la Innovación: Del Medio al Contenido Predictivo, eds. MartínezFernández, V. A., Juanatey-Boga, Ó., Puentes-Rivera, I., Rodríguez-Fernández, M. M., Sánchez-Amboage, E., Rodríguez-Vázquez, C. y Membiela-Pollán, M. (pp. 662-676). A Coruña: UDC / XESCOM. 
Martín, Víctor. 2012. «Cómo conseguir Engagement con tus seguidores». Retrieved February 8, 2018, from https://victormartinp.com/como-conseguirengagementcon-tus-seguidores/

Martínez Rolán, Xabier y Piñeiro, Teresa. 2017. «El uso de los memes en la conversación política 2.0. Una aproximación a una movilización efímera». Prisma Social, 18, 55-84.

Martínez Rolán, Xabier y Piñeiro, Teresa. 2016. «Los memes en el discurso de los partidos políticos en Twitter: análisis del Debate sobre el Estado de la Nación de 2015». Communication \& Society, 29(1): 145-160.

Molina-Cañabete, Juan Pedro y Magallón-Rosa, Raúl 2020. «Desinformación y periodismo científico. El caso de Maldita Ciencia». Revista Mediterránea de Comunicación. Mediterranean Journal of Communication, 11(2): 1-11

Montaña Blasco, M., Ollé Castellà, C. y Lavilla Raso, M. 2020. «Impacto de la pandemia de Covid-19 en el consumo de medios en España». Revista Latina de Comunicación Social, (78): 155-167.

Norstrom, R., y Sarna, P. 2021. «Memes de Internet en tiempos de confinamiento por Covid-19 en Polonia». Comunicar: Revista Científica de Comunicación y Educación, 29(67): 75-85.

Pelliser, Rosell y Pineda, Antonio. 2014. «Información política televisiva y espectacularización: un análisis comparativo de programas informativos y de entretenimiento». Estudios del Mensaje Periodístico, 20 (2).

Pérez Salazar, Gabriel, Aguilar Edwards, Andrea y Archilla, María Ernestina G. 2014. «El meme en Internet. Usos sociales, reinterpretación y significados a partir de Harlem Shake». Argumentos, 27(5): 79-102

Piñuel Raigada, Jose Luis. 2002. «Epistemología, metodología y técnicas del análisis de contenido». Sociolinguistic studies, 3(1): 1-42.

Re, F.A. 2014. «La política transmediática: nuevas formas de participación ciudadana». La trama de la comunicación, 18(1): 33-51.

Reche, Cristian. 2020, abril 13. «El Gobierno detecta 200 bulos sobre el coronavirus en España». Economía Digital. Disponible https://www.economiadigital.es/politica-y-sociedad/el-gobierno-detecta-200bulos-sobre-el-coronavirus-en-espana_20053134_102.html

Redondo, Miriam. 2018. Verificación digital para periodistas. Manual contra bulos y desinformación internacional. Barcelona: UOC.

Rodríguez, Delia. 2014. Memecracia. Los virales que nos gobiernan. Cómo las ideas contagiosas usan Internet para manipular a la gente. Madrid: Gestión 2000.

Roozenbeek, Jon \& Van der Linden, Sander. 2018. «The fake news game: actively inoculating against the risk of misinformation». Journal of Risk Research, 22(5): $570-580$.

Rothkopf, David. 2003, 11 de mayo. «When the Buzz Bites Back». The Washington Post. https://wapo.st/2xUFETk

Rúas Araújo, José y García Sanz, Francisco Javier. 2018. Persuasión y Neurociencias. Apelar al cerebro. Salamanca: Comunicación Social.

Salaverría, Ramón, Buslón, Nataly, López-Pan, Fernando, León, Bienvenido, LópezGoñi, Ignacio y Erviti, María-Carmen. 2020. «Desinformación en tiempos de pandemia: tipología de los bulos sobre la Covid-19». El profesional de la información, 29 (3), e290315. DOI: https://doi.org/10.3145/epi.2020.may.15

Salgado Andrade, Eva. 2021. «Memes y procesos de semiosis de la pandemia en México». Comunicación y Sociedad: 1-22, DOI: https://doi.org/10.32870/cys.v2021.7906 
Shifman, Limor. 2014. Memes in Digital Culture. Cambrigde, MA: The MIT Press.

Shifman, Limor y Thelwall, Mike. 2009. «Assessing global diffusion with Web Memetics: The spread and evolution of a popular joke». Jounal of The American Society for Information, Science and Technology. DOI: 10.1002/asi.21185

Stryker, Cole. 2011. Epic win for anonymous: How 4chan's army conquered the web. New York: The Overlook Press.

Tur-Viñes, Victoria. 2015. «Engagement, audiencias y series de ficción». En Rodríguez Ferrándiz, Raúl y Tur-Viñes, Victoria (Coords.), Narraciones sin fronteras. Cuadernos Artesanos de Comunicación, 81: 41-60.

Vélez, José Ivanhoe. 2007. Evolución en la tecnología: de la inteligencia artificial al meme. México D.F.: Palabra de Clío.

Verón, Eliseo. 1987. La semiosis social. Fragmentos de una teoría de la discursividad. Barcelona: Gedisa.

Wiggins, Bradley. 2019. The discursive power of memes in digital culture. Ideology, semiotics and intertextuality. London: Routledge. 